\title{
Alendronate Effect on the Prevention of Bone loss in Early Stages of Ankylosing Spondylitis: A Randomized, Double-Blind, Placebo-Controlled Pilot Study
}

\author{
Alireza Khabbazi ${ }^{1} ;$ Hamid $_{\text {Noshad }}{ }^{2, *} ;$ Sevil Gafarzadeh $^{3}$; Mehrzad Hajialiloo ${ }^{1}$; Susan Kolahi ${ }^{1}$ \\ ${ }^{1}$ Connective Tissue Diseases Research Center, Tabriz University of Medical Sciences, Tabriz, IR Iran \\ ${ }^{2}$ Chronic Kidney Disease Research Center, Tabriz University of Medical Sciences, Tabriz, IR Iran \\ ${ }^{3}$ Department of Internal Medicine, Tabriz University of Medical Sciences, Tabriz, IR Iran \\ ${ }^{*}$ Corresponding Author: Hamid Noshad, Chronic Kidney Disease Research Center, Tabriz University of Medical Sciences, Tabriz, IR Iran. Tel: +98-4115415023, E-mail: hamidnoshad1@ \\ yahoo.com
}

Received: February 4, 2014; Revised: February 28, 2014; Accepted: March 29, 2014

\begin{abstract}
Background: Ankylosing spondylitis (AS) is an inflammatory rheumatic disease that leads to a progressive ankylosis of vertebras and ossification of paravertebral ligaments. Bone loss and osteoporosis are amongst the important complications of AS, treatment of which is a challenging issue.

Objectives: This study aimed to clarify the effect of alendronate on the prevention of bone loss in patients with early AS.

Patients and Methods: In a randomized, double-blind, placebo-controlled study, 24 patients with early stages of AS were recruited in Emam Reza Hospital, Tabriz University of Medical Sciences. The diagnostic criteria of early AS were Schober's index $\geq 5$, normal hip joint in pelvic radiography, and absence or rarity of syndesmophytes in spine radiography (Taylor index $\leq 1$ ). The participants were randomly allocated to the treatment and control groups and received $70 \mathrm{mg} /$ week of alendronate and the same dose of placebo, respectively, for 12 months. Before and 12 months after the intervention, bone densitometry was performed from lumbar and pelvic region using the dualenergy X-ray absorptiometry (DEXA) method with Hologic QDR model instrument. Patients, physicians who prescribed the medications and those who interpreted the outcomes, and densitometry technicians were unaware of the assigned medication to each patient. Both groups received supplemental calcium (1000 mg/day) and vitamin $\mathrm{D}(400 \mathrm{mg} /$ day $)$.

Results: After 12 months of treatment, hip and lumbar bone mineral density differences were not statistically significant between study groups $(\mathrm{P}=0.061$ and $\mathrm{P}=0.112$, respectively). No case of clinically apparent vertebral and nonvertebral fracture were observed in the treatment and control groups.
\end{abstract}

Conclusions: Our results suggested that applying alendronate was ineffective in preventing bone loss in patients with early stages of AS.

Keywords:Spondylitis, Ankylosing; Bone Density; Alendronate

\section{Background}

Ankylosing spondylitis (AS) is an inflammatory rheumatic disease that is characterized by progressive ankylosis of vertebras and ossification of paravertebral ligaments and vertebral discs, which lead to the increased rigidity of the spine. The prevalence rate of AS is 7.4 to 31.9 per 10000 population $(1,2)$. Bone loss and osteoporosis are amongst the important complications of AS. Fractures, especially fractures of cervical spines, are more frequent in patients with AS than normal people (1.4\%-58\%) (3). Etiology of spinal fractures in AS are vertebras ankylosis and osteoporosis. Bone inflammation in AS leads to severe changes in bone turnover, which is the main cause of osteoporosis and the susceptibility to fractures (4). In a radiographic study, osteoporosis was detected in more than half of the patients with AS (5). The frequency of osteoporosis in AS was $18.7 \%$ to $62 \%$ in other similar studies (6-8). Bone loss is common in patients with long duration of AS; however, the prevalence of decreased bone mineral density (BMD) in patients with short disease duration is also high (9). In a systematic review, van der Weijden et al. showed that the prevalence of low BMD in the early stages of AS (disease duration $<10$ years) were $51 \%-54 \%$ for the femoral neck and the lumbar spine, respectively (10). Davey-Ranasinghe et al. revealed that the rate of the BMD reduction in AS was $2.2 \%$ per year, while in normal men it is about $0.7 \%$ per year (11). Ghozlani et al. showed that the frequency of spinal fracture in patients with and without osteoporosis is $29.6 \%$ and $11.1 \%$, respectively (12). Although

Implication for health policy/practice/research/medical education:

In order to reduce bone loss in patients with ankylosing spondylitis. The results of this study may help us perform better clinical trials for the prevention and treatment of osteoporosis in AS.

Copyright (c) 2014, Iranian Red Crescent Medical Journal; Published by Kowsar Corp. This is an open-access article distributed under the terms of the Creative Commons Attribution License, which permits unrestricted use, distribution, and reproduction in any medium, provided the original work is properly cited. 
osteoporotic fracture is more common in prolonged AS, it may be seen in early stages too (13); therefore, osteoporotic fracture might be the first presentation of AS (14). Vertebral fractures are associated with pain, deformity, and sometimes neurologic problems (15). Diagnosis of vertebral fracture may be missed due to the pain of the disease (16). Bone densitometry of hip with dual-energy $\mathrm{X}$-ray absorptiometry (DEXA) method is often used to diagnose osteoporosis in patients with AS (4). In AS, hip density is low and will reduce over time. Some studies showed that hip osteopenia is seen in $72 \%$ to $93 \%$ of the patients with AS (17). In early AS, density of vertebral spines reduces, but it increases over time due to formation of the syndesmophytes, which falsely increases vertebral bone content (6). Therefore, measuring lumbar spine density is accurate only in the early stages of AS.

Unlike patients with rheumatoid arthritis (RA), pharmaceutical treatment of osteoporosis in patients with AS is not yet a common practice. Data in support of the efficacy of osteoporosis treatment in AS are scarce. Bisphosphonates accumulate at the sites of increased bone turnover, inhibit bone resorption by inducing osteoclast apoptosis, and thereby increase bone density (18). Bisphosphonates were used widely for the treatment of osteoporosis in patients with AS, but there is not enough controlled study (16) regarding their effects on all forms of osteoporosis and their antiresorptive and anti-inflammatory effects (19). Current data show a continual demineralization in AS, which starts in the early stages of the disease; therefore, it is logical to prevent osteoporosis in early AS. No study was performed, to the best of our knowledge, to assess the efficacy of bisphosphonates in the prevention of bone loss and osteoporosis in early AS.

\section{Objectives}

Due to the high prevalence of osteoporosis and fractures in AS, we decided to design a pilot clinical trial to assess the effect of alendronate in preventing bone loss in early stages of AS.

\section{Patients and Methods}

This randomized, double-blind, placebo-controlled study was conducted in Emam Reza Teaching Hospital, Tabriz University of Medical Sciences (TUOMS), Tabriz, Iran, from July 2011 to October 2013. The study was approved by the Ethics Committee of the TUOMS and was registered with the Iranian Registry of Clinical Trials (IRCT) with the registration number of IRCT201212206975N3. All the patients referred to the outpatient clinic of Connective Tissue Diseases Research Center of TUOM who fulfilled the Assessment in Spondyloarthritis International Society (ASAS) classification criteria for axial spondyloarthropathies were eligible for our study (20).

\begin{tabular}{|c|c|c|c|}
\hline Variable & Alendronate $(\mathrm{n}=11)$ & $\operatorname{Placebo}(\mathbf{n}=13)$ & PValue \\
\hline Age, $y$ & $33.36 \pm 7.8$ & $32.85 \pm 7.6$ & 0.081 \\
\hline Gender, \% & & & 0.112 \\
\hline Male & 7 & 7 & \\
\hline Female & 4 & 6 & \\
\hline Duration of Disease, $y$ & $5.18 \pm 4.5$ & $5.54 \pm 4.8$ & 0.085 \\
\hline ESR, $\mathbf{m m} / \mathbf{h}$ & $37.8 \pm 27.5$ & $37.4 \pm 25.2$ & 0.211 \\
\hline Peripheral Arthritis, No. (\%) & $1(9.1)$ & 0 & 0.091 \\
\hline HLA-B27, No. (\%) & $9(81.8)$ & $12(92.3)$ & 0.118 \\
\hline Sacroiliitis Grade & & & 0.092 \\
\hline 0 & 0 & 1 & \\
\hline 1 & 2 & 1 & \\
\hline 2 & 7 & 2 & \\
\hline 3 & 2 & 4 & \\
\hline 4 & 0 & 0 & \\
\hline BASDAI & $7.34 \pm 2.6$ & $7.18 \pm 2.4$ & 0.071 \\
\hline BASMI & $3.20 \pm 1.30$ & $3.10 \pm 1.10$ & 0.062 \\
\hline Primary Lumbar BMD, mg/cm² & $0.99 \pm 0.09$ & $1.00 \pm 0.10$ & 0.112 \\
\hline Primary Hip BMD, mg/cm² & $0.79 \pm 0.16$ & $0.85 \pm 0.15$ & 0.061 \\
\hline
\end{tabular}

\footnotetext{
a Abbreviations: ESR, erythrocyte sedimentation rate; HLA-B27, human leukocyte antigen B27; BASDAI, Bath ankylosing spondylitis disease activity index; BASMI, Bath ankylosing spondylitis metrology index; BMD, bone mineral density.
} 
Khabbazi A et al.

\begin{tabular}{lcccc}
\hline \multicolumn{2}{l}{ Table 2. Bone Mineral Density in the Study Groups Before and After the Intervention ${ }^{\mathrm{a}}$} & & \\
\hline Intervention & $\begin{array}{c}\text { Primary Lumbar BMD, Lumbar BMD after 12 Months, } \\
\mathbf{g} / \mathbf{c m}^{2}\end{array}$ & $\begin{array}{c}\text { Primary Hip BMD, } \\
\mathbf{g} / \mathbf{c m}^{2}\end{array}$ & $\begin{array}{c}\text { Hip BMD After 12 Months, } \\
\mathbf{g} / \mathbf{c m}^{2}\end{array}$ \\
\hline Alendronate $(\mathbf{n}=\mathbf{1 1})$ & $0.99 \pm 0.09$ & $1.00 \pm 0.09$ & $0.85 \pm 0.15$ & $0.84 \pm 0.12$ \\
Placebo $(\mathbf{n}=\mathbf{1 3})$ & $1.00 \pm 0.10$ & $1.09 \pm 0.31$ & $0.79 \pm 0.16$ & $0.79 \pm 0.15$ \\
P Value & 0.112 & 0.114 & 0.061 & 0.098 \\
\hline
\end{tabular}

a Abbreviation: BMD, bone mineral density.

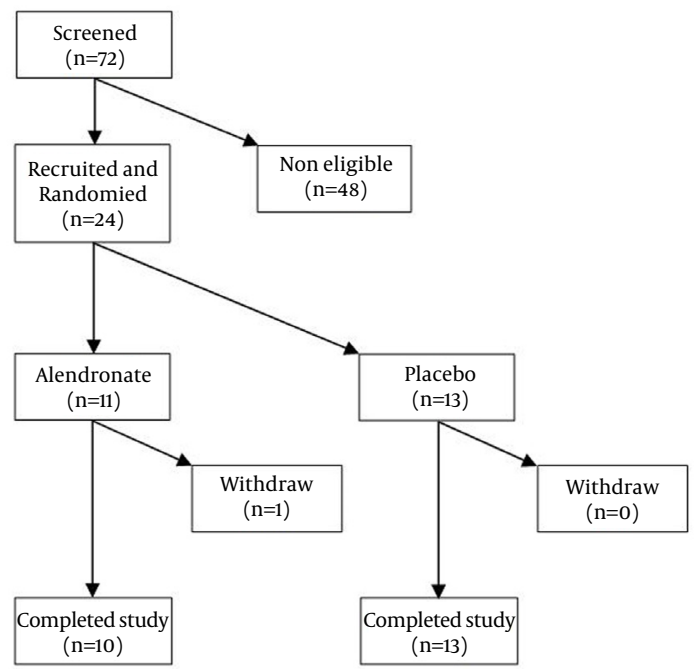

Figure 1. Recruitment and Enrollment of Study Participants and Outcomes

We used simple random allocation. All the patients in the early stage of AS with normal BMD or minimal reduction in bone density (T-score $\leq-1.5$ ) were enrolled in this study. The criteria for early stage of AS were Schober's index $\geq$ 5 , normal hip joint in pelvic radiography, and absence or rarity of syndesmophytes in spine radiography (Taylor index $\leq 1$ ). The exclusion criteria were previous history of spinal fracture, bisphosphonates and corticosteroids administration, pregnancy and lactation, and other conditions that might affect BMD like hypothyroidism, hyperthyroidism, osteomalacia, hyperparathyroidism, diabetes mellitus, and liver or kidney failure. Patients enrolled in this study after signing the written informed consents. Disease activity and axial status were evaluated by the Bath ankylosing spondylitis disease activity index (BASDAI) (21) and Bath ankylosing spondylitis metrology index (BASMI) (22), respectively. These patients were randomly allocated to two groups with Randlist software (DatInf GmbH, Tubingen, Germany). The treatment group received $70 \mathrm{mg} /$ week of alendronate (Ostomod, Modava Company, Iran) for 12 months and the control group received placebo with the same dose for the same period of time. Both groups received $1000 \mathrm{mg}$ of calcium and $400 \mathrm{mg}$ of vitamin D daily. Bone densitometry was performed with Hologic QDR model instrument (Hologic Inc., Waltham, MA, USA) before and 12 months after the intervention. Patients, physicians who prescribed or assessed the final outcome, and densitometry technicians were unaware of the type of the therapy. In order to control inflammation, we used antiinflammatory dose of nonsteroidal anti-inflammatory drugs (NSAID) with in both groups. Patients visited every two months and radiography was performed in the presence of the clinical signs of osteoporotic fracture. In this study, primary and secondary endpoints were BMD changes and clinical spinal and nonspinal fractures, respectively.

\subsection{Statistics}

A descriptive study was performed using SPSS v. 15.0 (SPPS Inc., Chicago, IL, USA). We used ANOVA, Chi square, and Fisher's exact test for analyzing data. In this study, $\mathrm{P}<$ 0.05 was considered statistically significant.

\subsection{Ethical Points}

Alendronate is a bisphosphonate and its main side effect is gastrointestinal complication. It is observed only in $5 \%$ of patients and is reversible after discontinuing. All the patients in this study signed a written consent and were aware of the complications.

\section{Results}

In this study, 72 patients with AS were screened for eligibility. Finally, 24 patients with early AS enrolled and were randomly allocated to the treatment and control groups. Table 1 shows the demographic and clinical characteristics of the patients and indicates no significant differences between the treatment and placebo groups at the beginning of the study. Only one patient did not complete the study (Figure 1).

The difference between the lumbar and hip BMD in the treatment and control groups was insignificant after 12 months (Table 2). The effects of alendronate on vertebral and femoral BMD are illustrated in Figure 2 and 3.

There was no clinically apparent vertebral and nonvertebral fracture in the treatment and control groups. No adverse events were observed. 


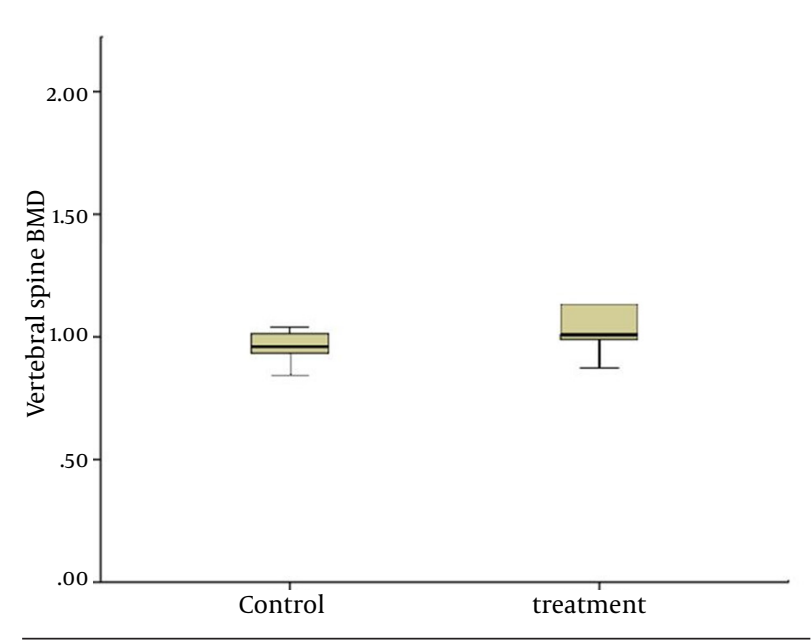

Figure 2. Vertebral Spines Bone Mineral Density After Intervention

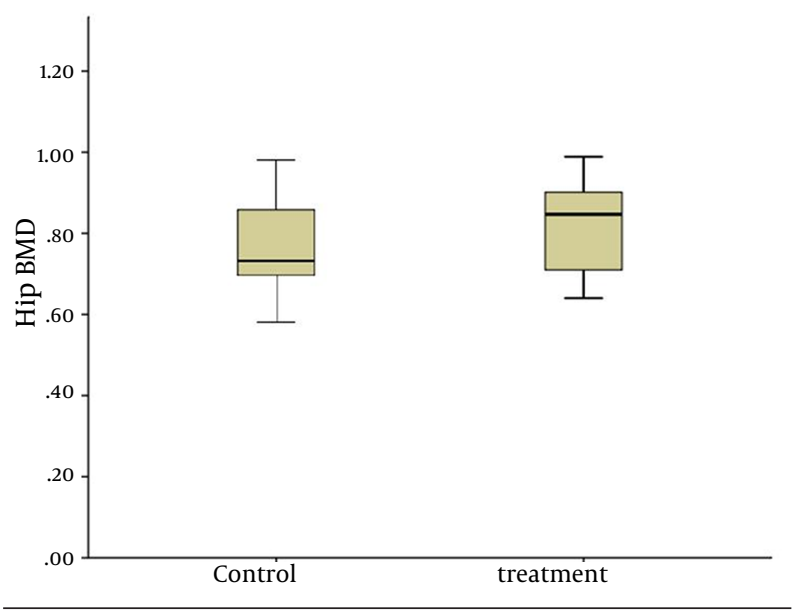

Figure 3. Hip Bone Mineral Density After Intervention

\section{Discussion}

Bone loss is an important complication of AS. The etiology of osteoporosis in AS is multifactorial and may involves different mechanisms at different stages of the disease. The most important mechanism is inflammation $(12,23,24)$. Other factors like immobilization due to pain, medications, and changes in vitamin D metabolism have also been mentioned (25). The role of reduced physical activity in patients with AS with syndesmophytes was discussed in the study by Karberg et al. (26). Genetic factors have been suspected and there is evidence that vitamin $\mathrm{D}$ receptor gene may contribute to BMD differences, bone metabolism, and inflammation processes in AS (27). Hormonal changes may also play a role. Franck et al. demonstrated a positive correlation between BMD at the femoral neck and serum free testosterone and free estradiol levels in men and women with AS, respectively (23). Inflammation plays an important role in the patho- genesis of bone loss in early stages of AS. In later stages of AS, mechanical factors such as decreased mobility play a more important role. Inflammatory cytokines like interleukin 1 (IL-1), interleukin 6 (IL-6) and tumor necrosis factor $\alpha$ (TNF- $\alpha$ ) with the induction of RANK-RANKL system activate osteoclasts. On the other hand, osteoprotegerin (OPG), which is a potent inhibitor of RANK-RANKL system, is reduced in patients with AS (17). Maillefert et al. suggested that persistent inflammation might be an etiologic factor of bone loss in AS, and that controlling inflammatory response with anti-inflammatory drugs might reduce the bone loss in patients with AS (28). In their study, Cairns et al. showed that treatment with pamidronate pulse reduced biochemical bone turnover markers and had small beneficial effect on disease activity measured by the BASDAI (29). Maksymowych showed that intravenous pamidronate had a dose dependent anti-inflammatory effect in AS (14). However, these studies did not consider the effect of pamidronate on BMD. Up to now, to the best of our knowledge, there is no published data concerning the effects of bisphosphonates on BMD in patients with AS.

The results of our study suggest that alendronate is ineffective in preventing bone loss in early stages of AS; however, further studies with larger sample size are needed in order to generalize the results. Combination therapies might be more useful in this regard and should be examined in clinical trials.

\section{Authors' Contribution}

Alireza Khabbazi: designing the study. Hamid Noshad: writing the manuscript. Sevil Gafarzadeh: data collection. Mehrzad Hajialiloo: data analysis. Susan Kolahi: preparing draft.

\section{References}

1. Caplan L, Clegg DO, Inman RD. Ankylosing spondylitis clinical registries: principles, practices and possibilities. Am J Med Sci. 2013;345(6):437-9.

2. Davatchi F, Jamshidi AR, Banihashemi AT, Gholami J, Forouzanfar MH, Akhlaghi M, et al. WHO-ILAR COPCORD Study (Stage 1, Urban Study) in Iran. J Rheumatol. 2008;35(7):1384.

3. Sinigaglia L, Varenna M, Girasole G, Bianchi G. Epidemiology of osteoporosis in rheumatic diseases. Rheum Dis Clin North Am. 2006;32(4):631-58.

4. Gilgil E, Kacar C, Tuncer T, Butun B. The association of syndesmophytes with vertebral bone mineral density in patients with ankylosing spondylitis. J Rheumatol. 2005;32(2):292-4.

5. Hanson CA, Shagrin JW, Duncan H. Vertebral osteoporosis in ankylosing spondylitis. Clin Orthop Relat Res. 1971;74:59-64.

6. Toussirot E, Wendling D. Bone mass in ankylosing spondylitis. Clin Exp Rheumato. 2000;18(5; SUPP/21):s16-20.

7. Bessant R, Keat A. How should clinicians manage osteoporosis in ankylosing spondylitis? J Rheumatol. 2002;29(7):1511-9.

8. Vasdev V, Bhakuni D, Garg MK, Narayanan K, Jain R, Chadha D. Bone mineral density in young males with ankylosing spondylitis. Int J Rheum Dis. 2011;14(1):68-73.

9. Singh HJ, Nimarpreet K, Das S, Kumar A, Prakash S, Ashima.. Study of bone mineral density in patients with ankylosing spondylitis. J Clin Diagn Res. 2013;7(12):2832-5.

10. van der Weijden MA, Claushuis TA, Nazari T, Lems WF, Dijkmans 
BA, van der Horst-Bruinsma IE. High prevalence of low bone mineral density in patients within 10 years of onset of ankylosing spondylitis: a systematic review. Clin Rheumatol. 2012;31(11):1529-35.

11. Davey-Ranasinghe N, Deodhar A. Osteoporosis and vertebral fractures in ankylosing spondylitis. Curr Opin Rheumatol. 2013;25(4):509-16.

12. Ghozlani I, Ghazi M, Nouijai A, Mounach A, Rezqi A, Achemlal L, et al. Prevalence and risk factors of osteoporosis and vertebral fractures in patients with ankylosing spondylitis. Bone. 2009;44(5):772-6.

13. Haibel H, Braun J, Maksymowych WP. Bisphosphonates--targeting bone in the treatment of spondyloarthritis. Clin Exp Rheumatol. 2002;20(6 Suppl 28):S162-6.

14. Maksymowych WP, Jhangri GS, Fitzgerald AA, LeClercq S, Chiu P, Yan A, et al. A six-month randomized, controlled, double-blind, dose-response comparison of intravenous pamidronate ( $60 \mathrm{mg}$ versus 10 $\mathrm{mg}$ ) in the treatment of nonsteroidal antiinflammatory drug-refractory ankylosing spondylitis. Arthritis Rheum. 2002;46(3):766-73.

15. Ulu MA, Cevik R, Dilek B. Comparison of PA spine, lateral spine, and femoral BMD measurements to determine bone loss in ankylosing spondylitis. Rheumatol Int. 2013;33(7):1705-11.

16. Mitra D, Elvins DM, Speden DJ, Collins AJ. The prevalence of vertebral fractures in mild ankylosing spondylitis and their relationship to bone mineral density. Rheumatology (Oxford). 2000;39(1):85-9.

17. Singh A, Bronson W, Walker SE, Allen SH. Relative value of femoral and lumbar bone mineral density assessments in patients with ankylosing spondylitis. South Med J.1995;88(9):939-43.

18. Luckman SP, Coxon FP, Ebetino FH, Russell RG, Rogers MJ. Heterocycle-containing bisphosphonates cause apoptosis and inhibit bone resorption by preventing protein prenylation: evidence from structure-activity relation ships in J774 macrophages.J Bone Miner Res. 1998;13(11):1668-78.

19. Robinson PC, Brown MA. Genetics of ankylosing spondylitis. Mol Immunol. 2014;57(1):2-11.
20. Rudwaleit M, van der Heijde D, Landewe R, Listing J, Akkoc N, Brandt J, et al. The development of Assessment of SpondyloArthritis international Society classification criteria for axial spondyloarthritis (part II): validation and final selection. Ann Rheum Dis. 2009;68(6):777-83.

21. Garrett S, Jenkinson T, Kennedy LG, Whitelock H, Gaisford P, Calin A. A new approach to defining disease status in ankylosing spondylitis: the Bath Ankylosing Spondylitis Disease Activity Index. Rheumatol. 1994;21(12):2286-91.

22. Jenkinson TR, Mallorie PA, Whitelock HC, Kennedy LG, Garrett SL, Calin A. Defining spinal mobility in ankylosing spondylitis (AS). The Bath AS Metrology Index.J Rheumatol. 1994;21(9):1694-8.

23. Franck H, Meurer T, Hofbauer LC. Evaluation of bone mineral density, hormones, biochemical markers of bone metabolism, and osteoprotegerin serum levels in patients with ankylosing spondylitis. J Rheumatol. 2004;31(11):2236-41.

24. Lange U, Teichmann J, Strunk J, Muller-Ladner U, Schmidt KL. Association of 1.25 vitamin D3 deficiency, disease activity and low bone mass in ankylosing spondylitis. Osteoporos Int. 2005;16(12):1999-2004.

25. El Maghraoui A. Osteoporosis and ankylosing spondylitis. Joint Bone Spine. 2004;71(4):291-5.

26. Karberg K, Zochling J, Sieper J, Felsenberg D, Braun J. Bone loss is detected more frequently in patients with ankylosing spondylitis with syndesmophytes. J Rheumatol. 2005;32(7):1290-8.

27. Wendling D. Bone loss in ankylosing spondylitis: can we put the puzzle together? J Rheumatol. 2005;32(7):1184-5.

28. Maillefert JF, Aho LS, El Maghraoui A, Dougados M, Roux C. Changes in bone density in patients with ankylosing spondylitis: a two-year follow-up study. Osteoporos Int. 2001;12(7):605-9.

29. Cairns AP, Wright SA, Taggart AJ, Coward SM, Wright GD. An open study of pulse pamidronate treatment in severe ankylosing spondylitis, and its effect on biochemical markers of bone turnover. Ann Rheum Dis. 2005;64(2):338-9. 